\title{
Analisis Kecepatan Putar, Durasi Gesek dan Tekanan Terhadap Kekuatan Tarik Hasil Pengelasan Gesek (Friction Welding)
}

\author{
M.Rizka Gita Firmansyah ${ }^{1)}$, Solichin $^{2)}$, Rr. Poppy Puspitasari ${ }^{3)}$ \\ ${ }^{1,2,3}$ Program Studi S1 Pendidikan Teknik Mesin Jurusan Teknik Mesin \\ ${ }^{1,2,3}$ Fakultas Teknik Universitas Negeri Malang \\ 1,2,3 Jalan Semarang No. 5, Malang 65145 \\ Email: m.rizka190395@gmail.com
}

\begin{abstract}
Abstrak: Pengelasan busur listrik elektroda terbungkus cocok digunakan untuk pelat-pelat datar. Namun untuk benda pejal sulit untuk dilakukan, apabila digunakan untuk benda pejal, maka, hasilnya kurang baik. Salah satu solusi untuk mengelas benda pejal yaitu menggunakan pengelasan gesek. Tujuan penelitian ini adalah untuk mengetahui kekuatan tarik hasil pengelasan gesek (friction welding) dengan variasi kecepatan putar, durasi gesek dan tekanan serta mengetahui bagaimana struktur mikro hasil pengelasan gesek (friction welding). Metode yang digunakan dalam penelitian ini menggunakan model one-shot case study dan analisis deskriptif. Analisis deskriptif meliputi hasil uji tarik dan struktur mikro hasil pengelasan gesek. Berdasarkan hasil penelitian yang dilakukan, nilai kekuatan tarik yang paling tinggi dihasilkan pada variasi kecepatan putar $2850 \mathrm{Rpm}$, durasi gesek 60 detik pada tekanan 8 Mpa. Sedangkan untuk hasil kekuatan tarik yang paling rendah yaitu dihasilkan pada variasi kecepatan putar $2850 \mathrm{Rpm}$, durasi gesek 80 detik pada tekanan $8 \mathrm{Mpa}$. Hasil foto mikro menunjukan bahwa tidak ada perubahan fase pada hasil pengelasan gesek hanya terjadi penghalusan partikel $\mathrm{Mg}_{2} \mathrm{Si}$ pada daerah $\mathrm{Zpd}$ dan $\mathrm{Zpl}$, sedangkan pada daerah Zud memiliki bentuk partikel $\mathrm{Mg}_{2} \mathrm{Si}$ yang sama dengan spesimen tanpa perlakuan.
\end{abstract}

Kata Kunci: Pengelasan gesek, Kekuatan tarik, struktur mikro

\begin{abstract}
Electric arc welding electrodes encased suitable for flat plates. But for rigid bodies is difficult to do, if they are used for rigid bodies, then, the result is less good. One solution to weld rigid bodies that use friction welding. The purpose of this study was to determine the tensile strength results of friction welding with the variation of rotational speed, friction time and pressure and to know how the microstructure of the results of friction welding. The method used in this study using the model of the one-shot case study and descriptive analysis. Descriptive analysis includes the results of tensile test and microstructure of friction welding results. Based on the results of research conducted, the value of the highest tensile strength is generated at $2850 \mathrm{rpm}$ rotational speed variation friction time of 60 seconds at a pressure of 8 $\mathrm{MPa}$. As for the results of the most low tensile strength that is generated at $2850 \mathrm{rpm}$ rotational speed variation, friction time 80 seconds at a pressure of $8 \mathrm{MPa}$. The results of micro photograph showed there was no change in phase on the outcome of the smoothing friction welding occurs only $\mathrm{Mg}_{2} \mathrm{Si}$ particles in the $\mathrm{Zpd}$ and $\mathrm{Zpl}$ area, while the area $\mathrm{Zud}$ have the same form $\mathrm{Mg}_{2} \mathrm{Si}$ particles with specimens without treatment.
\end{abstract}

Keyword: Friction welding, tensile strenght, micro structure

Pengelasan merupakan bagian yang tak terpisahkan dari pertumbuhan dan peningkatan industri, karena memegang peranan utama dalam rekayasa dan produksi logam. Pengelasan dengan elektroda terbungkus digunakan secara luas dikalangan masyarakat. Pengelasan dengan elektroda terbungkus cocok digunakan untuk pengelasan permukan plat-plat datar. Untuk benda pejal sangat sulit untuk dilakuakan. Jika digunakan untuk mengelas benda pejal, maka hasilnay kurang baik. Salah satu solusi untuk mengelas benda pejal adalah menggunakan pengelasan gesek (friction welding). Las gesek (friction welding) proses penyambungan logamnya tanpa pencairan, yang mana proses penyambungan terjadi akibat penggabungan laju putaran salah satu benda kerja dengan ujung benda kerja lainnya yang diberi tekanan dan akan menghasilkan panas yang akan melumerkan kedua permukaan yang bergesekan. Kecepatan putar, durasi gesek dan tekanan merupakan variabel yang sangat penting dalam pengelasan gesek (friction welding) karena variabel tersebut akan menentukan kualitas dan hasil pengelasan.

\section{METODE}

Penelitian ini menggunakan desain penelitian pre-experimental dengan menggunakan model one-shotcasestudy, dimana suatu kelompok sampel diberi sebuah perlakuan dan selanjutnya diobservasi hasilnya. Variabel penelitian yang 
digunakan dalam penelitian ini adalah 1) Variabel bebas dari penelitian ini adalah variasi kecepatan putar, durasi gesek dan tekanan. 2) Variabel terikat dari penelitian ini adalah hasil kekuatan tarik pengelasan gesek.

Teknik analisis data pada penelitian ini menggunakan analisis data deskriptif. Analisis deskriptif digunakan untuk menganalisis tentang pengujian tarik dan struktur mikro hasil pengelasan gesek (friction welding).

Spesimen uji tarik pada penelitian ini menggunakan SNI 07-0371-1998, ditunjukan pada gambar 1.

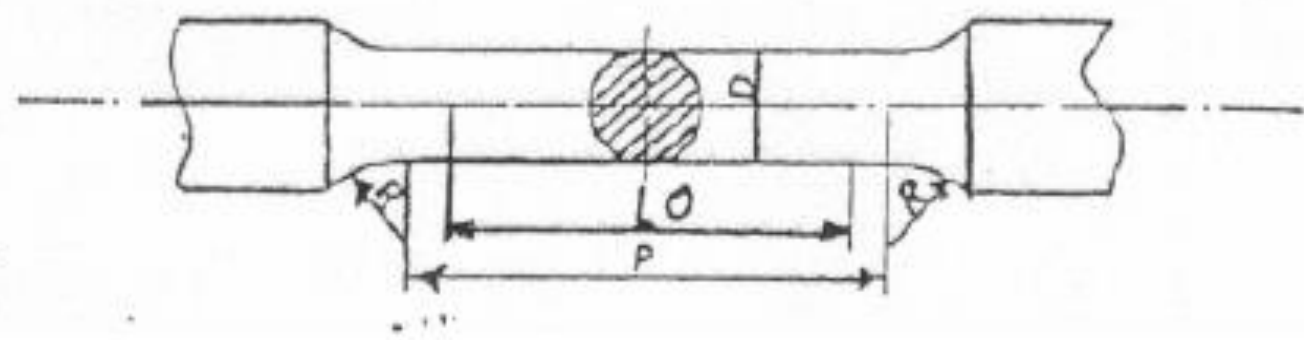

Gambar 1 Spesimen Uji Tarik SNI 07-0371-1998

Tabel 1 Ukuran Batang Uji Tarik SNI 07-0371-1998

\begin{tabular}{|l|l|l|l|}
\hline Diameter (D) & Panjang ukur (Lo) & Panjang paralel & Jari-jari bahu ${ }^{\circledR}$ \\
\hline 12,5 & 50 & Lebih kurang 60 & Maximum 15 \\
\hline
\end{tabular}

\section{HASIL DAN PEMBAHASAN}

\section{Uji Komposisi}

Sebelum dilakukan proses pengelasan gesek, komposisi bahan-bahan yang akan digunakan dalam proses pengelasan gesek (friction welding) dilakukan uji XRF ( $X$-Ray Flourescence). Pengujian XRF dilakukan untuk mengetahui komposisi dari suatu bahan yang digunakan.

Tabel 2 Hasil Uji Komposisi (XRF)

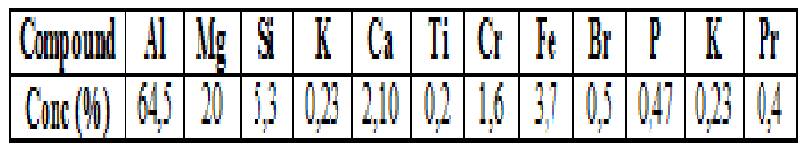

\section{Pengujian Kekuatan Tarik}

Hasil uji tarik dapat dilihat pada tabel 3.

Tabel 3. Hasil Uji Tarik

\begin{tabular}{lll}
\hline \multirow{2}{*}{ Kecepatan putar } & $\begin{array}{l}\text { Kekuatan tarik Al-Mg-Si } \\
\text { tekanan } 8 \text { Mpa }\end{array}$ & \\
\cline { 2 - 3 } & 60 detik & 80 detik \\
\hline \multirow{2}{*}{$2850 \mathrm{Rpm}$} & 12,80 & 12,81 \\
\cline { 2 - 3 } & 15,47 & 8,98 \\
\hline Rata-rata & 17,31 & 14,96 \\
\hline \multirow{2}{*}{$4000 \mathrm{Rpm}$} & $\mathbf{1 5 , 1 9}$ & $\mathbf{1 2 , 2 5}$ \\
\hline Rata-rata & 13,32 & 12,62 \\
\hline & 15,14 & 17,45 \\
\hline
\end{tabular}


Dari tabel 2 diatas didapatkan kekuatan tarik masing-masing variasi. Variasi Kecepatan putar 2850 dan durasi gesek 60 detik pada tekanan 8 Mpa memiliki kekuatan tarik sebesar 15,19 Kgf, kekuatan tarik variasi kecepatan putar 2850 dan durasi gesek 80 detik pada tekanan 8 Mpa sebesar 12,25 Kgf, variasi kecepatan putar 4000 dan durasi gesek 60 detik pada tekanan 8 Mpa memiliki kekuatan tarik sebesar 13,23, dan variasi kecepatan putar 4000 dan durasi gesek 80 detik pada tekanan 8 Mpa memiliki kekuatan tarik sebesar 14,31 Kgf.

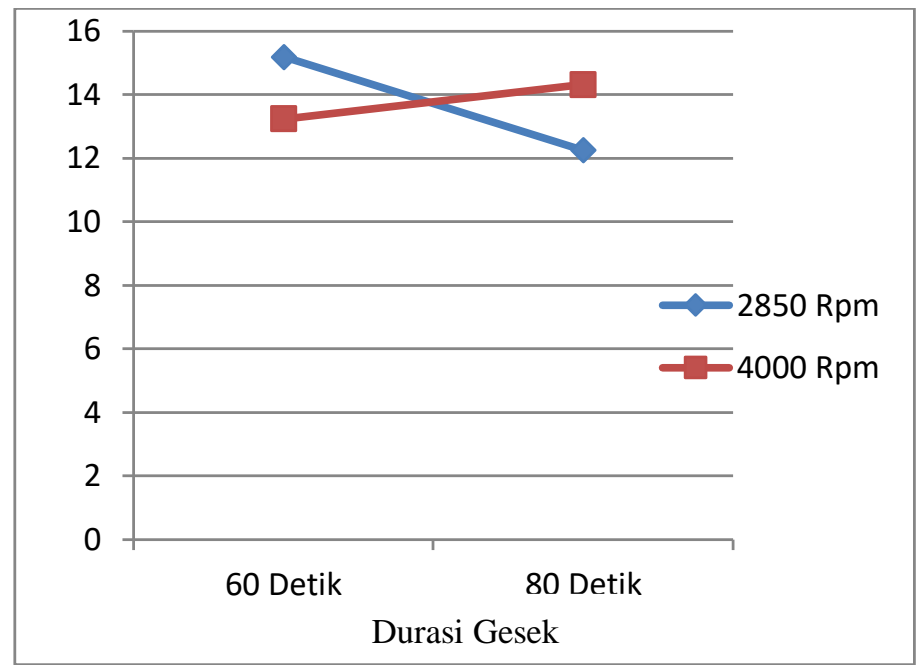

Gambar 2 Kekuatan Tarik Rata-rata Seluruh Hasil Pengelasan Gesek

Pada putaran rendah dengan durasi yang lebih singkat akan menghasilkan kekuatan tarik yang tinggi. Bila pada putaran rendah ini durasi gesek dinaikan lagi maka kekuatan tariknya akan menurun. Hal tersebut karena pada saat durasi gesek yang lebih kecil temperatur puncak dapat dihasilkan. Tapi dengan ditambahnya durasi gesek temperatur gesekan akan kembali memurun. Hal tersebutlah yang mempengaruhi kekuatan tarik sambungan las gesek, (Kumar dkk: 2017).

Untuk putaran tinggi cenderung memiliki kekuatan tarik yang lebih besar, jika durasi geseknya besar pula. Hal tersebut karena pada putaran tinggi dengan durasi gesek yang kecil belum tercapai temperatur puncak. Sedangkan dengan ditambahnya durasi gesek menjadi lebih besar dari durasi gesek sebelumnya tapi dengan putaran yang sama, maka akan dapat menghailkan temperatur puncak. Namun bila durasi gesek ditingkatkan lagi kemungkinan kekuatan tariknya akan menurun. (Kumar, dkk: 2014).

\section{Struktur Mikro}

Menurut ASM Hand Book Metalography Microstructures partikel hitam yang merata pada matriks alumunium adalah $\mathrm{Mg}_{2} \mathrm{Si}$ dan partikel yang berwarna abu-abu adalah $\mathrm{Fe}_{3} \mathrm{SiAl}_{12}$ (Setyawan dan Dwileksana: 2014).

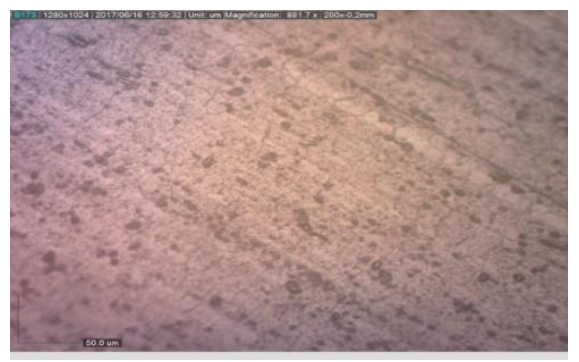

Gambar 3 Foto Mikro Spesimen Tanpa Perlakuan

Jika dilihat pada gambar 3 foto mikro spesimen tanpa perlakuan, maka dapat dilihat bahwa antar partikel $\mathrm{Mg}_{2} \mathrm{Si}$ sangat jaraknya sangat jarang.dan memiliki bentuk partikel yang cenderung bulat.
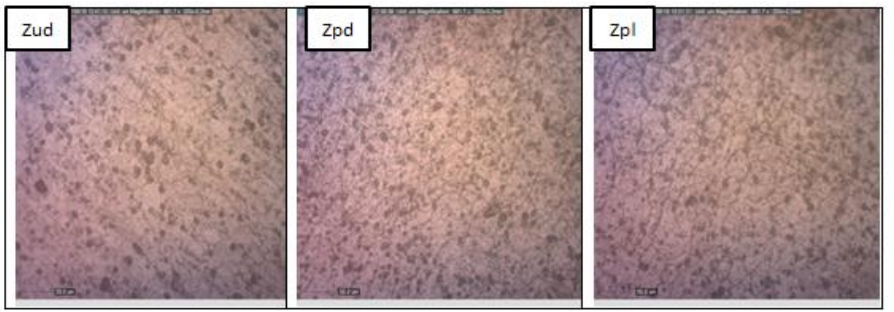
Gambar 4 Foto Mikro Daerah Zud, Zpd (HAZ) dan Zpl pada Variasi 2850 Rpm dan 60 S pada 8 Mpa

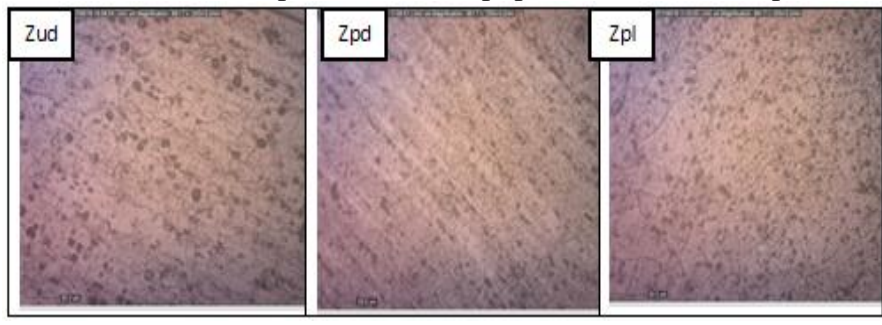

Gambar 5 Foto Micro Daerah Zud, Zpd (HAZ) dan Zpl pada Variasi 2850 Rpm dan 80 S pada 8 Mpa

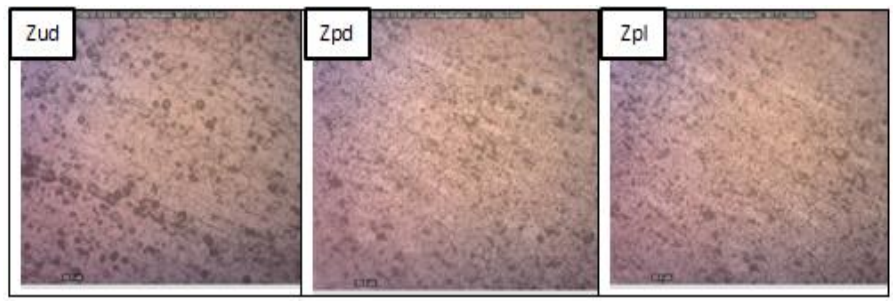

Gambar 6 Foto Micro Daerah Zpl, Zpd (HAZ) dan Zud pada Variasi 4000 Rpm dan 60 S pada 8 Mpa

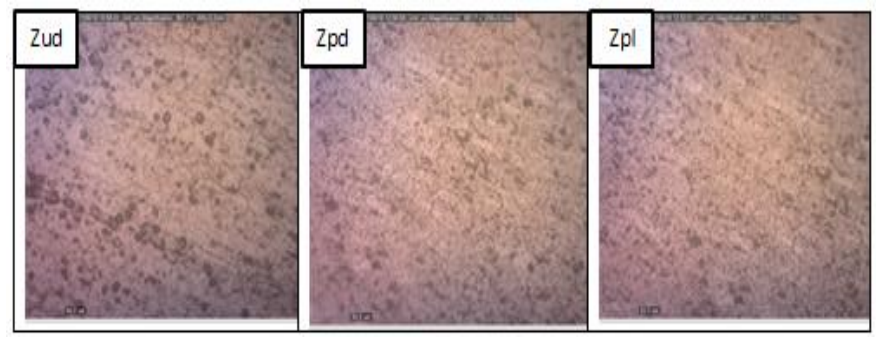

Gambar 7 Foto Micro Daerah Zpl, Zpd (HAZ) dan Zud pada Variasi 400 Rpm dan 80 S pada 8 Mpa

Pada pengelasan gesek (friction welding) hanya terjadi penghalusan butir-butir atom dan tidak terjadi perubahan fase karena pada pengelasan ini tidak menggunakan logam pengisi, (Sugito dkk: 2016). Daerah Zud, Zpd dan Zpl akan memiliki struktur micro yang berbeda, sebab, pada saat proses pengelasan ketiga daerah tersebut mendapatkan perlakuan yang berbeda (Prasetyono dan Subiyanto: 2012).

Bila dilihat dari gambar 4, 5, 6 dan 7 diatas, maka dapat dilihat bahwa daerah Zud cenderung memiliki ukuran butir yang lebih besar sedangkan pada daerah Zpd dan Zpl cenderung mempunyai ukuran butir yang lebih kecil. Itu menandakan bahwa pada daerah Zpd dan Zpl hanya mengalami penghalusan butir-butir dan tidak terjadi perubahan fase karena pada pengelasan ini tidak menggunakan logam pengisi, (Sugito dkk: 2016). Adanya perbedaan pada daerah Zud, Zpd dan Zpl dikarenakan logam las telah mengalami proses pemanasan akibat gesekan dan proses penempaan. Pemansan maupun proses penempaan akan dapat merubah struktur mikro, (Sunyoto, 2012).

Semaikin tinggi suhu atau temperatur kedua permukaan pada saat bergesekan maka butir juga semakin halus.Perbedaan bentuk partikel disebabkan oleh berbedanya temperatur pada saat bergeseknya kedua permukaan ketika proses pengelasan berlangsung. Hasil menunjukkan bahwa setiap parameter pengelasan memiliki dampak yang signifikan terhadap struktur mikro, kekerasan mikro dan kekuatan, (Basher dan Ahmad 2014).

\section{SIMPULAN DAN SARAN}

Dari data dan penelitian yang dilakukan oleh penulis dapat disimpulkan bahwa:

\section{Kekuatan Tarik}

- Kekuatan tarik tertinggi dihasilkan pada variasi kecepatan putar 2850 dan durasi gesek selama 60 detik pada tekanan 8 Mpa yaitu sebesar 15,19 Kgf 
- $\quad$ Kekuatan tarik terendah dihasilkan pada variasi kecepatan putar 2850 dan durasi gesek selama 80 detik pada tekanan 8 Mpa yaitu sebesar 12,25 Kgf.

\section{Struktur Mikro}

- Struktur mikro pada daerah Zud sama dengan struktur spesimen tanpa perlakuan

- Terajadi penghalusan struktur $\mathrm{Mg}_{2} \mathrm{Si}$ pada daerah $\mathrm{Zpd}$ dan $\mathrm{Zpl}$

- Semakin kecil atau halus partikel $\mathrm{Mg}_{2} \mathrm{Si}$ maka semakin besar kekuatan tarik sambungan hasil las gesek

- Semakin banyak terlihat partikel $\mathrm{Mg}_{2} \mathrm{Si}$ pada hasil pengelasan maka kekuatan tariknya juga semakin besar.

\section{SARAN}

- Untuk penelitian selanjutnya dapat di variasikan tekanan gesek pengelasan, diameter spesimen dan sudut chemper spesimen pengelasan.

- Untuk penelitian selanjutnya sebaiknya dilakukan juga foto makro agar daerah Zud, Zpl dan Zpd dapat terlihat dengan jelas.

- Untuk Penelitian selanjutnya dapat menggunakan bahan yang lain.

\section{DAFTAR RUJUKAN}

Basher, Uday M dan Ahmad. 2014. Joint Properties of friction Welded 6061 Aluminum Alloy / YSZ-Alumina Composite at Low Rotational Speed. http://www.sciencedirect.com/. Online. Diakses 15 November 2017.

Kumar, Ranvijay dkk. 2017. Friction Welding For T he Manufacturing of PA6 and ABS Structures Reinforced With Fe Particles http://www.sciencedirect.com/. Online. Diakses 15 November 2017

Kumar, Sachin dkk. 2014. A Research Paper on Temperature Modelling of Friction Welding of Aluminium and Stainless Steel-304. http://www.sciencedirect.com/. Online. Diakses 15 November 2017.

Prasetyono, Sigied \& Subiyanto, Hari, 2012. Pengaruh Durasi Gesek, Tekanan Gesek dan Tekanan Tempa Terhadap Impact Strenght Sambungan Las Gesek Langsung Pada Baja Karbon AISI 1045. Online. http://digilib.its.ac.id/public/ITS-paper-24016-2108100519Paper.pdf. Diakses 03 Januari 2017.

Setyawan, F.W dan Dwileksana, Dedi. 2014. Analisis Sifat Mekanik Dan Struktur Mikro Aluminium Paduan Al-Mg-Si Hasil Pengelasan Friction Welding Dengan Variasi Kecepatan Putar. http://repository.unej.ac.id/handle/123456789/57465?show=full. Online. Diakses 15 November 2017.

Sugito, Bibit dkk. 2016, Pengaruh Kedalaman Pin (Depth Plung)Terhadap Kekuatan Sambungan Las Pada Pengelasan Gesek AL 5083. http://digilib.its.ac.id/public/ITS-paper-24016-2108100519-Paper.pdf. Online. Diakses 06 Juni 2017.

Sunyoto, Budi Luwar. 2012. Penerapan Teknologi Las Gesek Friction Welding) Dalam Proses Penyambungan Dua Buah Pipa Logam Baja Karbon Rendah. http://www.e jurnal.com/2014/08/penerapan-teknologi-las-gesek-friction.html. Online. Diakses 05 Juli 2017. 